\title{
Serology Testing: The Dark Horse in SARS COV2 Pandemic
}

\author{
Rateesh Sareen $^{1, *}$, G N Gupta ${ }^{2}$, Anshika Yadav ${ }^{3}$, and Shyam Saini ${ }^{4}$ \\ ${ }^{1}$ Consultant, Department of Pathology and Transfusion Medicine, Santokba Durlabhji Memorial Hospital \& Research Center, Jaipur, Rajasthan, \\ India \\ ${ }^{2}$ Head of the department, Department of Pathology and Transfusion Medicine, Santokba Durlabhji Memorial Hospital \& Research Center, \\ Jaipur, Rajasthan, India \\ ${ }^{3}$ DNB Resident, Department of Pathology and Transfusion Medicine, Santokba Durlabhji Memorial Hospital \& Research Center, Jaipur, \\ Rajasthan, India \\ ${ }^{4}$ Senior technical manager, Department of Pathology and Transfusion Medicine, Santokba Durlabhji Memorial Hospital \& Research Center, \\ Jaipur, Rajasthan, India
}

*Corresponding author: Rateesh Sareen, DNB, MBBS, Consultant, Department of Pathology and Transfusion Medicine, Santokba Durlabhji Memorial Hospital \& Research Center, Jaipur, Rajasthan, India, Email: drrateeshsareen@yahoo.co.in

Received: 04 Oct, 2020 | Accepted: 09 Dec, 2020 | Published: 14 Dec, 2020

Citation: Sareen R, Gupta GN, Yadav A, Saini S (2020) Serology Testing: The Dark Horse in SARS COV2 Pandemic. J Clin Lab Med 5(2): dx.doi. org/10.16966/2572-9578.136

Copyright: (c) 2020 Sareen R, et al. This is an open-access article distributed under the terms of the Creative Commons Attribution License, which permits unrestricted use, distribution, and reproduction in any medium, provided the original author and source are credited.

\section{Abstract}

Introduction: SARS COV-2 pandemic has been a nightmare for medical, political and social systems all over the world, right from the point of initial diagnosis, treatment protocols, anticipated vaccine development and prevention strategies.

Material and Methods: The current paper focuses on the role of serological testing to gold standard RT PCR for detection of SARS COV2 infection. The retrospective study was done at the tertiary care hospital in Western India after institutional ethics committee approval using ICMR approved Rapid method, Standard Q COVID-19 IgM/IgG Duo test kit (SD Biosensor, Republic of Korea) in addition to standard RT PCR, the gold standard for diagnosis.

Results: There were total 553 patients, 154 were RT PCR positive indicating infection with SARS-COV2. The serology testing was positive in $53.71 \%($ $297 / 553)$ and negative in $45.03 \%$ (249/553). Among the 249 negative serology cases, $93.57 \%$ (233/249) had RT-PCR negative where as $6.43 \%$ (16/249) cases were RT-PCR positive. Of the serologically positive group $44.44 \%(132 / 297)$ later were found to be positive on RT-PCR. Those RT PCR negative cases with positive IgM or both IgM \& IgG positive serology along with the presence of COVID 19 related symptom or CT lung findings were considered as positive for COVID 19 i.e., False Negative RT PCR. The sensitivity and specificity of combined RT-PCR was $90.87 \% \& 86.08 \%$ as against $85.71 \%$ \& $58.65 \%$ for standalone serology.

Conclusion: Therefore antibody tests supplemented with RT-PCR are powerful tools for detection of SARS COV-2 infection. The role of serology in additional detection of SARS COV 2 infection as well as identification of false positive RT PCR which might be due to contamination or prolonged viral shedding cannot be undermined. It is sure that with more validation studies and research serology will find strong footing in future.

Keywords: COVID-19 testing; RT PCR; Serology

\section{Introduction}

The rapid global spread of acute respiratory syndrome corona virus (SARS-COV2) has caused unprecedented strain on health care systems and economies with substantial disruption of daily life. It has been agreed upon that the elimination of virus is no longer feasible rather the focus is now on flattening the peak of SARS-COV2 emergence curve with gradually lifting of restrictions. There exists a knowledge gap with regard to immunity and protection afforded in the community. Timely accurate diagnosis is of paramount importance as it not only helps in providing appropriate treatment but also helps in limiting the spread of infection and could serve as a pack for elimination of virus from society. Till date clearance of virus and effective full proof measures for preventing spread are lacking, it is therefore important that understanding of viral duration in nasopharynx and the immune response in time course is fully understood [1].

Reverse transcriptase polymerase chain reaction (RT PCR) has been the available diagnostic modality to confirm diagnosis of SARSCOV2 infection using throat or nasopharyngeal swabs with negligible false negatives [2] however there are reported cases where in spite of RT-PCR negative typical lung radiological findings were observed. False negative RT-PCR may be attributed to several factors like low viral load in upper respiratory tract samples from COVID19 patients [3], collection technique of nasopharyngeal swab which require 
expertise [4] and variations in performance of PCR test. Serology testing on the other hand is quick and less technically demanding [5] and correlate with the disease severity [6]. The sero conversion rates are nearly $100 \%$ after $10-14$ days of infection $[7,8]$.

In such circumstances serological tests should not be outwardly rejected. In the current paper we have made an attempt to reclassify RT PCR negative patients with positive serology (Ig M positive alone or IgM \& IgG both positive) as SARS-COV2 positive based on presence or absence of typical symptoms associated with or suspected of SARS COV2 infection. Another advantage of serological test is that they can identify previous infection by SARS-COV2. There is no doubt that serological tests have been developed rapidly and the urgent demand has compelled manufacturers to cut short on rigorous evaluation process which has ultimately generated uncertainty about testing accuracy [9]. The serology test should not be rejected outwardly. Serology tests will find a strong footing in coming days with growing need, better understanding of the immune response involved and better availability of more reliable test kits.

The goal of our study is to examine the sensitivity and specificity of serology testing for COV-2 infection and compare it with combination of RT-PCR and serology. It is need of hour that RNA PCR test is combined with antibody test to improve sensitivity of detection; the present study is an endeavor in this direction [10].

\section{Material and Methods}

The retrospective study was performed at the tertiary care hospital in western India in a 550 bedded hospital with National Accreditation Board of health care providers (NABH) accreditation after institutional ethics committee approval. The data was retrieved for all patients who were tested for SARS COV-2 infection by serology (Rapid method, Standard Q COVID-19 IgM/IgG Duo-SD Biosensor, Republic of Korea) and RT PCR (True NAT, Molbio diagnostics Pvt Ltd, India) methods over past three months from May- July, 2020. The laboratory data included results of antibody testing against SARS COV-2 and RT PCR.

\section{Inclusion criteria}

Patients who had serology and PCR done for SARS COV-2 detection, whether symptomatic or asymptomatic

\section{Exclusion criteria}

Those with only RT PCR test done for SARS COV-2 infection

\section{Testing Strategy}

Nasopharyngeal swab (NP swab) was taken from all suspected patients, transported in media for immediate RT PCR testing. The serology was performed on blood samples. $5 \mathrm{ml}$ blood was collected in EDTA vial (BD Vacutainer) or in plain red topped vial. The plain vial sample was centrifuged to $1500-2000 \mathrm{~g}$ for 10 minutes, serum separated and antibody testing done whereas EDTA blood was directly used for samples in EDTA vial.

\section{Antibody test}

The antibody tests have been approved by ICMR subjected to use after approval by respective state governments for diagnosis of SARS COV2 infection, some states in India using serology test for diagnosis whereas others not $[11,12]$. The antibody testing as not approved by the state government was therefore done only for study purpose using ICMR approved standard Q COVID 19 IgM /IgG Duo test kit (SD, Biosensor, Republic of Korea) which is a rapid chromatography immunoassay for qualitative detection of specific antibodies to SARS COV-2 in human serum, plasma or whole blood as an initial screening test. It has two pre coated lines, 'C' control line, ' $\mathrm{G}$ ' test line for COVID-19 IgG device and similar ' $C$ ' control \& ' $M$ ' test line for IgM device on surface of nitro cellulose membrane. The SARS COV2 antibodies in the specimen interact with recombinant COVID-19 nucleo capsid protein with colloidal gold particles making antibody antigen gold parallel complex which migrates on the membrane via capillary action until the test line, where it is captured by monoclonal antihuman IgG antibody or Monoclonal anti human IgM antibody. Violet test line in the result window will differ if SARS COV-2 antibody is present in specimen. The control line is used for procedural control and should always appear if the test procedure is performed properly to ascertain that the reagent is working properly.

\section{Antigen test}

ICMR also approved standard Q COVID19 Ag kit developed by SD biosensor (South Korea) by an advisory dated 14/06/2020 [13]. It is a rapid chromatographic immunoassay for qualitative detection of specific antigens to SARS COV2. The nasopharyngeal swab is immersed in viral extraction buffer provided with the kit. The buffer inactivates the virus thereby reducing biosafety requirements. The test can be interpreted as positive or negative after 15 minutes of pulling the sample into the well by appearance of test and control lines which can be read by naked eye requiring no specialized equipments. The high specificity and low sensitivity made ICMR recommend its use as a point of care diagnostic assay for testing in combination with gold standard RT PCR in

A. Containment zones or hot spots,

B. Health care settings for symptomatic suspected patients, asymptomatic patients undergoing chemotherapy, HIV positive immunocompromised, malignancy, transplant recipients or $>65$ years of age with co-morbidities,

C. Asymptomatic patients undergoing aerosol generating surgical/non surgical procedures.

The statistical analysis was performed using online free statistical calculator (Med calc). Sensitivity, specificity for SARS COV-2 detection using serology test as well as combined serology and RT PCR was calculated. Chi square test were performed on numerator data with $\mathrm{p}$ value $<0.05$ considered statistically significant.

\section{Molecular testing}

The SARS COV2 testing strategy by Indian council of Medical Research (ICMR), the apex body in India through its advisory dated 232/06/2020 [11] has emphasized on Real time PCR, True NAAT and CBNAAT as testing platforms for SARS COV2 infection. The RT PCR has been the front line test. True NAAT and CBNAAT have also been approved for testing at grass root level as the customized cartridges have now made it possible to employ these tests with shorter turnaround time of 30-60 minutes in comparison to 4-5 hours with RT PCR. The use of closed system and viral lysis buffer to inactivate the virus eliminates safety issues with both true NAAT and CB NAAT testing. We used multiplex assay using single step E gene and orfla gene for detection of SARS COV2 infection (Molbio diagnostics Pvt Ltd, India), as approved by ICMR.

\section{Results}

The aim of our study was to compare serology \& RT PCR for screening of SARS COV-2 infection. Our prime focus was on initial 
Table 1a: Age distribution of subjects.

\begin{tabular}{|c|c|}
\hline Age group & Number of cases \\
\hline $0-10$ & 0 \\
\hline $20-$ Oct & 4 \\
\hline $20-30$ & 7 \\
\hline $30-40$ & 148 \\
\hline $40-50$ & 170 \\
\hline $50-60$ & 99 \\
\hline $60-70$ & 58 \\
\hline $70-80$ & 44 \\
\hline $80-90$ & 3 \\
\hline Mean age & $\mathbf{4 7 . 7}$ years \\
\hline & \\
\hline & 58 \\
\hline
\end{tabular}

Table 1b: Sex distribution of subjects.

\begin{tabular}{|l|l|}
\hline \multicolumn{1}{|c|}{ Mean age } & \\
\hline Male & $382(69.08 \%)$ \\
\hline Female & $171(30.92 \%)$ \\
\hline
\end{tabular}

Table 2: Distribution of cases as per serology and PCR test results (First scenario).

\begin{tabular}{|l|c|c|c|}
\hline & PCR Positive & PCR Negative & Grand Total \\
\hline Serology Negative & 16 & 233 & 249 \\
\hline Serology Positive & 132 & 165 & 297 \\
\hline Serology recovered & 6 & 1 & 7 \\
\hline Grand Total & 154 & 399 & 553 \\
\hline
\end{tabular}

screening for SARS COV-2 infection in both the symptomatic and asymptomatic patient so that an early triage is possible preventing infection risk to health care workers and other patients in hospital settings. We performed single first point of contact RT PCR test and corresponding serology test therefore it was not possible for evaluation of specificity \& sensitivity of RT PCR as multiple RT PCR from patients who initially tested negative RT PCR was not done. The patient characteristics are shown in table $1 \mathrm{a} \& 1 \mathrm{~b}$.

FIRST SCENARIO: For evaluation of standalone serology sensitivity \& specificity (Table 2)

A. All RT PCR positive were taken as true positives and similarly for RT PCR negatives that were considered as true negative.

B. IgM alone positive cases and $\operatorname{IgM}$ as well as $\operatorname{IgG}$ positive ones were considered as positives

C. Alone IgG positive were considered as recovered patient

D. True positives comprised of cases that were both serology and RT PCR positive

E. Serology positive and RT PCR negative were considered as false positive

Based on our assumptions for interpretation of serology and RT PCR test, the true positives were 132, true negatives 234 (including one recovered on serology), false positive 165 and false negative 22 (including 6 recovered on serology). The statistical results of Serology testing are shown in table 3 . The sensitivity \& specificity were $85.71 \%$ and $58.65 \%$ respectively.
Table 3: Statistical calculations for standalone Serology test.

\begin{tabular}{|l|c|c|}
\hline \multicolumn{1}{|c|}{ Statistic } & Value & $\mathbf{9 5 \%} \mathbf{C l}$ \\
\hline Sensitivity & $85.71 \%$ & $79.17 \%$ to $90.83 \%$ \\
\hline Specificity & $58.65 \%$ & $53.64 \%$ to $63.52 \%$ \\
\hline Positive Likelihood Ratio & 2.07 & 1.81 to 2.37 \\
\hline Negative Likelihood Ratio & 0.24 & 0.16 to 0.36 \\
\hline Disease prevalence & $27.85 \%$ & $24.15 \%$ to $31.79 \%$ \\
\hline Positive Predictive Value & $44.44 \%$ & $41.18 \%$ to $47.76 \%$ \\
\hline Negative Predictive Value & $91.41 \%$ & $87.75 \%$ to $94.05 \%$ \\
\hline Accuracy & $66.18 \%$ & $62.07 \%$ to $70.12 \%$ \\
\hline
\end{tabular}

Table 4: Distribution of cases as per serology and PCR test results (Second scenario).

\begin{tabular}{|l|c|c|c|}
\hline & PCR Positive & PCR Negative & Grand Total \\
\hline Serology Negative & 16 & 233 & 249 \\
\hline Serology Positive & 132 & 75 & 207 \\
\hline Serology Recovered & 6 & 1 & 7 \\
\hline Symptom with serology + & 0 & 90 & 90 \\
\hline Grand Total & 154 & 399 & 553 \\
\hline
\end{tabular}

Table 5: Symptoms taken suspicious of SARS COV2 infection [13-15].

\begin{tabular}{|l|c|c|}
\hline Cough & Breathlessness & Sore throat \\
\hline Fever & Body ache & Nausea \\
\hline Vomiting & Diarrhea & Chest pain \\
\hline Hemoptysis & Abdominal pain & Sputum \\
\hline
\end{tabular}

Table 6: CT findings suspicious of SARS COV2 infection.

Ground-glass opacities

Vascular enlargement

Bilateral abnormalities

Lower lobe involvement, and posterior predilection

SECOND SCENARIO: For combined sensitivity \& specificity evaluation of serology and RT PCR-(Table 4)

- The above assumptions (a to c) remain the same; however Serology positive and RT PCR negative were considered as true positive.

For scenario 2, our emphasis was on picking up cases on serology that were positive and had negative RT PCR, a thorough search for symptoms suggestive of COVID 19 infection along with CT chest findings suggestive of COVID 19 infection were taken. Those cases with symptoms (Table 5) and CT Chest suggestive (Table 6) of COVID-19 infection with negative RT PCR but positive serology, were included in true positive category. There were in all 90 such cases out of 165 . The true positives were 222 (including serology positive \& RTPCR negative patients with symptoms \& or CT findings suggestive of COVID 19 infection), False positives- 75, true negatives-233 and false negatives 22 (including 6 recovered patients with negative RT PCR). The sensitivity \& specificity of combined serology and PCR was $90.98 \%$ and $75.73 \%$ respectively (Table 7) [13-15]. 
Table 7: Statistical calculations for Combined (Serology test \& RT PCR test).

\begin{tabular}{|l|c|c|}
\hline Statistic & Value & $\mathbf{9 5 \%} \mathbf{C l}$ \\
\hline Sensitivity & $90.98 \%$ & $86.67 \%$ to $94.26 \%$ \\
\hline Specificity & $75.73 \%$ & $70.55 \%$ to $80.40 \%$ \\
\hline Positive Likelihood Ratio & 3.75 & 3.07 to 4.58 \\
\hline Negative Likelihood Ratio & 0.12 & 0.08 to 0.18 \\
\hline Disease prevalence & $44.12 \%$ & $39.94 \%$ to $48.37 \%$ \\
\hline Positive Predictive Value & $74.75 \%$ & $70.77 \%$ to $78.35 \%$ \\
\hline Negative Predictive Value & $91.41 \%$ & $87.66 \%$ to $94.09 \%$ \\
\hline Accuracy & $82.46 \%$ & $79.03 \%$ to $85.54 \%$ \\
\hline
\end{tabular}

\section{Discussion}

The entire medical fraternity, international health care agencies, regulatory bodies are aiming at successful control of SARS-COV2 spread, which could only be achieved by using an accurate, rapid and cost effective method for SARS COV2 detection. The problem of underestimation of asymptomatic patients with COVID-19 infection results gives a false sense of security adding to spread of infection. There are studies from literature that have pointed out that asymptomatic patients might have short viral shedding duration or may have viral nucleic acid loads that are undetected on RT-PCR and serology testing [14]. The proportion of asymptomatic COVID-19 patients on diamond princess cruise ship was estimated to be $50.5 \%$ and proportion among the evacuated Japanese citizens was estimated to be $30.8 \%[15,16]$. The asymptomatic individuals that are overlooked in an epidemic pose serious threat to prevention and control $[17,18]$.

We reclassified PCR negative and serology patients as SARS COV2 positive patients only for the study purpose, without affecting their treatment protocols .In our study of total 553 patients, 154 were RT PCR positive indicating infection with SARS-COV2. The serology testing was positive in $53.71 \%(297 / 553)$ and negative in $45.03 \%$ (249/553). Among the 249 negative serology cases, 93.57\% (233/249) had RT-PCR negative where as $6.43 \%(16 / 249)$ cases were RT-PCR positive which were missed by serology but captured by RT-PCR. Of the serologically positive group $44.44 \%$ (132/297) later were found to be positive on RT-PCR. We then analyzed the 165 cases which were serology positive and RT-PCR negative. This group was scrutinized for COVID19 related symptoms (Table 5) and diagnostic CT lung scan findings (Table 6). Those RT PCR negative cases with positive IgM or both IgM \& IgG positive serology along with the presence of COVID 19 related symptom or CT lung findings were considered as positive for COVID 19 i.e., False Negative RT PCR. This strategy enabled us to additionally identify 90 subjects as COVID19 infected individuals. The sensitivity and specificity of combined RT-PCR was $90.87 \%$ \& $86.08 \%$ as against $85.71 \%$ \& $58.65 \%$ for standalone serology. Therefore antibody tests supplemented with RT-PCR are powerful tools for detection of SARS COV-2 infection. The combination test is superior as it results in diagnosis of more COVID-19 patients. There is no doubt that by testing single sample by RT-PCR the interpretation of the test has to be carefully done. The false negative RT PCR tests have devastating consequence on health and social care setting [19]. The literature studies vary from $2-33 \%$ in rates of false negative RT PCR for COVID 19 infection. Valdiva A, et al [20] found IgM reactivity in $3 / 6$ of the follow up sera of COVID patients that were RT PCR negative and after repeated serology IgM testing established diagnosis of COVID 19 infection.
The $7^{\text {th }}$ edition of guideline for COVID-19 by national commission of the people republic of China recommended serological testing [21]. The studies by Zhao J, et al [8], Geurvlsvunkessel CH, et al [22], Kruttgen A, et al [23], Lassanevere R, et al [24] determined antibody response to SARSCOV-2 and found good sensitivity and specificity. The literature studies point out that patients with kidney disease and ongoing hemodialysis gave false negative serology test, the effect was similar to those in detection of anti hepatitis HCV antibodies [25], Elsherif A, et al [26] \& Tate J, Ward G [27]. Tate and ward in their study highlighted the role of heterophile antibody in interference with test assays by competitive mechanism causing false positive results. Heterophile antibodies were seen in elderly, pregnant woman and cancer patients, they might interfere with serological testing.

In developing countries where there are inadequate resources including trained manpower total reliance on RT-PCR method for detection of COVID-19 infection could pose a serious threat as mostly single RT-PCR tests are employed and repeat testing of RTPCR negative patients is not possible as the testing facilities are already stretched beyond their capacity. Study by Guo L, et al [28] have shown that $51.9 \%$ patients were positive by single RT-PCR and positivity rate increased to $98.6 \%$ following antibody assays on RT-PCR negative individuals. A false negative RT-PCR test will allow infectious patients to go back to community and will defeat all efforts of containing virus. It is therefore of utmost importance that antibody testing shouldn't be considered as a useless test rather combining it with RT-PCR would improve diagnostic efficacy not only in later but in early stages as supported in studies by Liu L, et al [14]. Serological assays are useful in determining immune status of health care workers, understanding the immune response to SARS COV 2 and for epidemiological studies [29]. These assays help in identification of individuals with required antibody response against SARS COV-2 who can be potential donors for convalescent plasma therapy [30] and also for vaccine development [7].

We understand that larger, prospective, multicenteric studies will be required to formulate more evidence based guidelines [31-34] which is challenging during the ongoing pandemic. The uncertainty around SARS COV-2 diagnostics [35,36] will remain as even the gold standard PCR negative does not reliably preclude SARS-COV2 infection and there is decline in clinical sensitivity of PCR with days post symptom onset [37]. We could not get repeat RT- PCR test for initial negative cases and therefore this is one of the limitation we had in our study. The limited availability of testing facilities, time constraints and lack of recording of date for initial onset of symptoms could have been a useful anchor point [38]. The need for more prospective and systematically obtained repeated parallel RT-PCR is all needed and more studies are required [39].

There were 6 patients with persistent RT positivity despite a serology recovery (Table 8 ). There could be several explanationstechnical issues like contamination (during sampling, during PCR amplicons or reagent cross contamination) and even cross reaction with other virus genetic material could result in false positive PCR [39]. The cross contamination was a serious issue so much and so that CDC US, withdrew testing kits in early March 2020. In UK the rates of false positivity are around $0.8 \%-4.0 \%[40,41]$. Yet another cause for persistent false positive RT PCR could be prolonged viral shedding which lasts till weeks following recovery however there is paucity of literature studies to suggest that low level viral RNA detection is infectious unless laboratory gets a positive culture [42]. In our study the 6 patients after $15^{\text {th }}$ day of diagnosis were completely asymptomatic with reversal of inflammatory markers to normal levels. There was 
Table 8: Patient profile- PCR Positive with IgM Negative \& IgG Positive.

\begin{tabular}{|c|c|c|c|c|c|c|c|c|c|}
\hline No & $\begin{array}{l}\text { Age } \\
\text { (Yr) }\end{array}$ & Presenting symptoms & $\begin{array}{l}\text { Symptom } \\
\text { after } \\
\text { treatment }\end{array}$ & $\begin{array}{c}\text { Time since } \\
\text { first PCR } \\
\text { (Days) }\end{array}$ & Vital parameters & $\begin{array}{c}\text { CRP* } \\
\text { (mg/dl) }\end{array}$ & $\begin{array}{c}\mathrm{IL}-6^{* *} \\
(\mathrm{pg} / \mathrm{ml})\end{array}$ & $\begin{array}{l}\text { Ferritin" } \\
\text { (ng/ml) }\end{array}$ & $\begin{array}{c}\text { d-dimer }{ }^{\# \#} \\
\text { ( ug/ml) }\end{array}$ \\
\hline A & 40 & Fever, Nausea & Nil & 22 & $\begin{array}{c}\text { Afebrile, BP-120/80 mm } \\
\mathrm{Hg}, \mathrm{SpO}_{2}-98 \%\end{array}$ & 0.6 & 2.2 & 178 & 0.20 \\
\hline B & 35 & Cough, Breathlessness & Nil & 19 & $\begin{array}{c}\text { Afebrile, BP-110/70 mm } \\
\text { Hg, SpO }-99 \%\end{array}$ & 0.5 & 1.6 & 212 & 0.10 \\
\hline C & 55 & Breathlessness & Nil & 21 & $\begin{array}{c}\text { Afebrile, BP-110/70 mm } \\
\mathrm{Hg}, \mathrm{SpO}_{2}-99 \%\end{array}$ & 1.1 & 1.8 & 335 & 0.30 \\
\hline D & 62 & Breathlessness, Cough & Nil & 20 & $\begin{array}{c}\text { Afebrile, BP-120/80 mm } \\
\text { Hg, SpO }-98 \%\end{array}$ & 0.7 & 3.2 & 369 & 0.10 \\
\hline $\mathbf{E}$ & 53 & Fever, sore throat & Nil & 24 & $\begin{array}{c}\text { Afebrile, BP-110/70 mm } \\
\text { Hg, SpO }-97 \%\end{array}$ & 0.8 & 3.7 & 354 & 0.30 \\
\hline $\mathbf{F}$ & 75 & Fever, Cough & Nil & 21 & $\begin{array}{c}\text { Afebrile, } \mathrm{BP}-120 / 80 \mathrm{~mm} \\
\mathrm{Hg}, \mathrm{SpO}_{2}-98 \%\end{array}$ & 0.4 & 1.5 & 269 & 0.20 \\
\hline
\end{tabular}

*_CRP-C Reactive protein; Normal reference range (0-1 mg/dl); Immonosorbent assay; **-Interleukin-6; Normal reference range (0-4.4 pg/ml); Advia centaur CP; \# -normal reference range (17.9-464 ng/ml); Vitros 3600 (ortho clinical diagnostics); \#\#-Normal reference range (0-0.50 ug/ml); Stago Compaq

absence of COVID related symptom (Table 8). And these findings prompted us to consider these patients as recovered implying that the RT PCR was false positive as they were IgG positive. SARS-COV-2/ COVID-19 pandemic represent a dynamic situation and we hope that subsequent research reports would add significant knowledge to existing literature.

\section{Conclusion}

The better understanding of immune process in SARS COV2 infection will help in utilizing serological assays which no doubt have role in modeling public health policies and hold promise in absence of definite treatment or vaccine [43]. Any testing modality is not free of limitations; it mandates that their application is done by considering numerous factors like timing of testing, purpose of testing etc. Serological assays as on now are like seedlings that could not sustain on their own in absence of RT PCR but still their complimentary role cannot be undermined. It is sure that with more validation studies and research serology will find strong footing in future.

\section{References}

1. Long QX, Liu BZ, Deng HJ, Wu GC, Deng K, et al. (2020) Antibody responses to SARS-CoV-2 in patients with COVID-19. Nat Med 26: 845-848.

2. Yang $\mathrm{Y}$, Yang MH, Shen CG, Wang FX, Yuan J, et al. (2020) Evaluating the accuracy of different respiratory specimens in the laboratory diagnosis and monitoring the viral shedding of 2019- nCoV infections. MedRxiv.

3. Chan JF, Yuan SF, Kok KH, Wang To KK, Chu H, et al. (2020) A familial cluster of pneumonia associated with the 2019 novel coronavirus indicating person-to-person transmission: a study of a family cluster. The Lancet 395: 514-523.

4. Zou LR, Ruan F, Huang MX, Liang L, Huang H, et al. (2020) SARSCoV-2 viral load in upper respiratory specimens of infected patients. N Engl J Med 382: 1177-1179.
5. Peeling RW, Wedderburn CJ, Garcia PJ, Boeras D, Fongwen N, et al. (2020) Serology testing in the COVID-19 pandemic response. The Lancet Infectious Diseases 20: E245-E249.

6. Chen X, Pan Z, Yue S, Yu F, Zhang J, et al. (2020) Disease severity dictates SARS-CoV-2-specific neutralizing antibody responses in COVID-19. Signal Transduct Target Ther 5: 180.

7. Okba NMA, Muller MA, Li W, Wang C, Geurtsvankessel $\mathrm{CH}$, et al (2020) Severe acute respiratory syndrome coronavirus 2-specific antibody responses in coronavirus disease 2019 patients. Emerg Infect Dis 26: 1478-1488.

8. Zhao J, Yuan Q, Wang H, Liu W, Liao X, et al. (2020) Antibody responses to SARS-CoV-2 in patients of novel coronavirus disease 2019. Clin Infect Dis 71: 2027-2034.

9. Maxmen A (2020) The researchers taking a gamble with antibody tests for coronavirus. Nature.

10. Wang $P$ (2020) Combination of serological total antibody and RTPCR test for detection of SARS-CoV-2 infections. J Virol Methods 283:113919.

11. Revised Guidelines for TrueNat testing for COVID-19 (2020) ICMR.

12. ADVISORY Newer Additional Strategies for COVID-19 Testing (2020) ICMR.

13. Advisory on Use of Rapid Antigen Detection Test for COVID-19 (2020) ICMR.

14. Liu L, Liu W, Zheng $Y$, Jiang X, Kou G, et al. (2020) A preliminary study on serological assay for severe acute respiratory syndrome coronavirus 2 (SARS-CoV-2) in 238 admitted hospital patients. Microbes Infect 22: 206-211.

15. Nishiura H, Kobayashi T, Miyama T, Suzuki A, Jung S-M, et al. (2020) Estimation of the asymptomatic ratio of novel coronavirus infections (COVID-19). Int J Infect Dis 94: 154-155. 
16. Mizumoto K, Kagaya K, Zarebski A, Chowell G (2020) Estimating the asymptomatic proportion of coronavirus disease 2019 (COVID-19) cases on board the Diamond Princess cruise ship, Yokohama, Japan, 2020. Euro Surveillance 25: 2000180.

17. Lai C-C, Liu YH, Wang C-Y, Wang Y-H, Hsueh S-C, et al. (2020) Asymptomatic carrier state, acute respiratory disease, and pneumonia due to severe acute respiratory syndrome coronavirus 2 (SARS-CoV-2): facts and myths. J Microbiol Immunol Infect 53: 404 412

18. Qiu J (2020) Covert coronavirus infections could be seeding new outbreaks. Nature.

19. Arevalo-Rodriguez I, Buitrago-Garcia D, Simancas-Racines D, Zambrano-Achig, del Campo R, et al. (2020) False-negative results of initial RT-PCR assays for COVID-19: a systematic review. MedRxiv.

20. Valdivia A, Torres I, Huntley D, Alcaraz MJ, Albert E, et al. (2020) Diagnostic significance of SARS-CoV-2 IgM positive/IgG negative antibody profile in symptomatic patients with suspected COVID-19 testing negative by RT-PCR. J Infect.

21. China National Health Commission (2020) Diagnosis and Treatment Protocol for Novel Coronavirus Pneumonia (Trial Version 7). Chinese Medical Journal.

22. GeurtsvanKessel $\mathrm{CH}$, OKBA NMA, Igloi Z, Embregts CWE, Laksono $B M$, et al. (2020) Towards the next phase: evaluation of serological assays for diagnostics and exposure assessment. MedRxiv.

23. Krüttgen $A$, Cornelissen CG, Dreher $M$, Hornef $M$, Imohl $M$, et al. (2020) Comparison of four new commercial serologic assays for determination of SARS-CoV-2 IgG. J Clin Virol 128: 104394.

24. Lassaunière R, Frische $A$, Harboe ZB, Nielsen AC, Fomsgaard A, et al. (2020) Evaluation of nine commercial SARS-CoV-2 immunoassays. medRxiv.

25. WHO Director-General's opening remarks at the media briefing on COVID-19 - 11 March 2020.

26. El-Sherif A, Elbahrawy A, Aboelfotoh A, Abdelkarim $M$, Saied Mohammad AG, et al. (2012) High false-negative rate of anti-HCV among Egyptian patients on regular hemodialysis. Hemodial Int 16: 420-427.

27. Tate J, Ward G (2004) Interference in immunoassay. Clin Biochem Rev 25: 105-120.

28. Guo L, Ren L, Yang S, Xiao M, Chang D, et al. (2020) Profiling Early Humoral Response to Diagnose Novel Coronavirus Disease (COVID-19). Clin Infect Dis 71: 778-785.

29. Amanat F, Stadlbauer D, Strohmeier S, Nguyen THO, Chromikova V, et al. (2020) A serological assay to detect SARS-CoV-2 seroconversion in humans. Nature Medicine.
30. To KK-W, Tsang OT-Y, Leung W-S, Tam AR, Wu T-C, et al. (2020) Temporal profiles of viral load in posterior oropharyngeal saliva samples and serum antibody responses during infection by SARSCoV-2: an observational cohort study. Lancet Infect Dis 20: 565-574.

31. Wang D-W, Hu B, Hu C, Zhu F, Liu X, et al. (2020) Clinical Characteristics of 138 Hospitalized Patients With 2019 Novel Coronavirus-Infected Pneumonia in Wuhan, China. JAMA 23: 1061-1069.

32. Wan S-X, Yi Q-J, Fan S-B, Lv J-L, Zhang X-X, et al. (2020) Characteristics of lymphocyte subsets and cytokines in peripheral blood of 123 hospitalized patients with 2019 novel coronavirus pneumonia (NCP). MedRxiv.

33. Nicola M, O'Neill N, Sohrabi C, Khan M, Agha M, et al. (2020) Evidence based management guideline for the COVID-19 pandemic - Review article. Int J Surg 77: 206-216.

34. Pascarella G, Strumia A, Piliego C, Bruno F, Del Buono R, et al. (2020) COVID-19 diagnosis and management: a comprehensive review. J Intern Med 288: 192-206.

35. Tang YW, Schmitz JE, Persing DH, Stratton CW (2020) Laboratory Diagnosis of COVID-19: Current Issues and Challenges. J Clin Microbiol 58.

36. Weissleder R, Lee $\mathrm{H}$, Ko J, Pittet MJ (2020) COVID-19 diagnostics in context. Sci Transl Med 12.

37. Liu W, Liu L, Kou G, Zheng Y, Ding Y, et al. (2020) Evaluation of Nucleocapsid and Spike Protein-based Enzyme-Linked Immunosorbent Assays for detecting antibodies against SARSCoV-2. J Clin Microbiol 58: e00461-e00520.

38. Sethuraman N, Jeremiah SS, Ryo A (2020) Interpreting Diagnostic Tests for SARS-CoV-2. JAMA 323: 2249-2251.

39. Bermingham WH, Wilding T, Beck S, Huissoon A (2020) SARS-CoV-2 serology: Test, test, test, but interpret with caution! Clin Med (Lond) 20: $365-368$

40. European Centre for Disease Prevention and Control (2020) Transmission of COVID-19.

41. Mayers C, Baker K (2020) Impact of false-positives and falsenegatives in the UK's COVID-19 RT-PCR testing programme.

42. Cohen AN, Kessel B (2020) False positives in reverse transcription PCR testing for SARS-CoV-2. MedRxiv.

43. Gronvall G, Connell N, Kobokovich A, West R, Warmbrod KL, et al. (2020) Developing a National Strategy for Serology (Antibody Testing) in the United States. Johns Hopkins Center for Health Security. 